This document was prepared in conjunction with work accomplished under Contract No. DE-AC09-96SR18500 with the U.S. Department of Energy.

This work was prepared under an agreement with and funded by the U.S. Government. Neither the U. S. Government or its employees, nor any of its contractors, subcontractors or their employees, makes any express or implied: 1 . warranty or assumes any legal liability for the accuracy, completeness, or for the use or results of such use of any information, product, or process disclosed; or 2 . representation that such use or results of such use would not infringe privately owned rights; or 3 . endorsement or recommendation of any specifically identified commercial product, process, or service. Any views and opinions of authors expressed in this work do not necessarily state or reflect those of the United States Government, or its contractors, or subcontractors. 


\title{
Plutonium Feed Impurity Testing in Lanthanide Borosilicate (LaBS) Glass
}

\author{
Kevin M. Fox, James C. Marra, Thomas B. Edwards, Elizabeth N. Hoffman and \\ Charles L. Crawford \\ Savannah River National Laboratory, Aiken, SC, U.S.A.
}

\begin{abstract}
A vitrification technology utilizing a lanthanide borosilicate (LaBS) glass is a viable option for dispositioning excess weapons-useable plutonium that is not suitable for processing into mixed oxide (MOX) fuel. A significant effort to develop a glass formulation and vitrification process to immobilize plutonium was completed in the mid-1990s. The LaBS glass formulation was found to be capable of immobilizing in excess of $10 \mathrm{wt} \% \mathrm{Pu}$ and to be tolerant of a range of impurities. A more detailed study is now needed to quantify the ability of the glass to accommodate the anticipated impurities associated with the $\mathrm{Pu}$ feeds now slated for disposition.

The database of $\mathrm{Pu}$ feeds was reviewed to identify impurity species and concentration ranges for these impurities. Based on this review, a statistically designed test matrix of glass compositions was developed to evaluate the ability of the LaBS glass to accommodate the impurities. Sixty surrogate LaBS glass compositions were prepared in accordance with the statistically designed test matrix. The heterogeneity (e.g. degree of crystallinity) and durability (as measured by the Product Consistency Test - Method A (PCT-A)) of the glasses were used to assess the effects of impurities on glass quality.
\end{abstract}

\section{INTRODUCTION}

In the aftermath of the Cold War, the United States has identified an excess of up to 50 metric tons (MT) of weapons-useable plutonium. The Department of Energy (DOE) was to construct both a Mixed Oxide Fuel Fabrication Facility (MFFF) and a Plutonium Immobilization Program (PIP) facility to disposition this material. In April 2002, DOE decided not to construct the PIP facility and to solely proceed with the construction of the MFFF facility with a focus only on the disposition of weapons-grade plutonium to meet the non-proliferation agreement between Russia and the United States. This action resulted in up to 13 metric tons of DOEOffice of Environmental Management (DOE-EM) owned, weapons-useable, plutonium-bearing materials having no clear disposition path.

Vitrification utilizing a lanthanide borosilicate (LaBS) glass appears to be a viable option to disposition excess weapons-useable plutonium that is not suitable for processing into mixed oxide (MOX) fuel. A significant effort to develop a glass formulation and vitrification process to immobilize plutonium was completed in the mid-1990s to support the PIP. The LaBS glass formulation was found to be capable of immobilizing in excess of $10 \mathrm{wt} \% \mathrm{Pu}$ and to be very tolerant of impurities [1-2]. Thus, this waste form could be suitable for the disposition of plutonium owned by the DOE-EM that may not be well characterized and that may contain high levels of impurities. However, the relative tolerance of the glass composition to the various impurities associated with current $\mathrm{Pu}$ feeds slated for disposition needs to be studied. 
The present study focuses on the development of a composition envelope that describes the solubility of various impurities in the LaBS glass. To define this envelope, a series of glass compositions was selected, fabricated and characterized to evaluate the solubility of various impurity elements and their effects on crystallization and durability. To facilitate laboratory experiments, the glasses were formulated with $\mathrm{Hf}$ as a surrogate for $\mathrm{Pu}$. $\mathrm{Pu}$ glass testing will be performed on select compositions for comparison with the results of the surrogate testing. Concurrent with the glass formulation studies, melter testing is being conducted to evaluate the effects of impurities on processing [3].

\section{EXPERIMENTAL DETAILS}

\section{Development of the Impurity Test Matrix}

A detailed analysis of the anticipated $\mathrm{Pu}$ feeds to be immobilized in waste glass was provided by Moore and Allender [4]. The projected impurity types and concentrations described in that report were used as the basis for defining the compositions of the glasses to be fabricated for this study.

The report by Moore and Allender projected the concentrations of more than 70 possible elements as impurities in the $\mathrm{Pu}$ feed. This list was reduced to seventeen elements based on several criteria. First, all of the elements with a best estimate maximum concentration of 18,000 $\mu \mathrm{g} / \mathrm{g}$ and above were included. Impurities that had relatively low concentrations and would be expected to have little impact on glass chemistry were excluded (e.g. the solubility of silicon in the glass should not be an issue and Si was removed from the impurity list). Next, sulfur and lead were included since these elements are known to typically have low solubility in the LaBS glass. Finally, selenium and cesium were included again due to low solubility being expected for these elements in LaBS glass.

Table I lists the impurities that were chosen using these criteria. For each of the elements in this table, an interval of possible concentrations is given. This interval represents the possible concentration of the indicated element as an impurity in the feed. The lower limits were defined by rounding the best estimate concentration for $50 \%$ of the projected feeds to either zero or, in the case of chlorine, to $5000 \mu \mathrm{g} / \mathrm{g}$. The upper limits were defined by the greater of either the best estimate maximum concentration or the best estimate concentration for $98 \%$ of the projected feeds. These values were rounded to the nearest thousand $\mu \mathrm{g} / \mathrm{g}$. The concentration values were then converted to mass fractions of the Pu feed, as listed in Table I.

The chemical form of each of these impurity elements in the feed was not necessarily known, but there were some restrictions that were imposed on the approach used in developing the test matrix for this study. The first restriction imposed was a constraint on the overall mass of impurities in the feed. Moore and Allender provide total impurity concentration data for 2200 containers of the anticipated Pu feed based on Prompt Gamma Analysis and chemical estimates from laboratory samples [4]. Using these data, the total mass of the impurities was set to $35 \%$ of the overall $\mathrm{Pu}$ feed stream. This value was chosen to represent a worst case impurity concentration based on the data provided by Moore and Allender. Thus, on a mass basis, a design point for the study had to satisfy the constraint that the sum of the mass fractions of all of the impurities of that design point had to add to 0.35 .

An additional restriction on the composition of the impurities making up a design point was required to address the issue of charge balance for that design point. If each of the 
impurities of Table I were converted to an oxide as a result of the vitrification process and if the feed were batched in these oxides to introduce the appropriate concentrations of all of the elements of Table I, then there would be no need for a charge balance restriction. However, for $\mathrm{Cl}, \mathrm{F}$, and $\mathrm{S}$ this is not the case, and the batching of the impurities that involve one or more of these elements imposed a constraint of the amounts of other impurities of Table I that had to be present to provide a charge balance for the impurity concentration.

Table I. Impurities and Their Possible Concentrations as Mass Fractions in the Feed

\begin{tabular}{|c|c|c|}
\hline Element & $\begin{array}{c}\text { Lower } \\
\text { Limit }\end{array}$ & $\begin{array}{c}\text { Upper } \\
\text { Limit }\end{array}$ \\
\hline $\mathrm{Cl}$ & 0.05 & 0.35 \\
\hline $\mathrm{Ta}$ & 0 & 0.315 \\
\hline $\mathrm{Mg}$ & 0 & 0.35 \\
\hline $\mathrm{K}$ & 0 & 0.11 \\
\hline $\mathrm{Fe}$ & 0 & 0.08 \\
\hline $\mathrm{Na}$ & 0 & 0.096 \\
\hline $\mathrm{F}$ & 0 & 0.195 \\
\hline $\mathrm{Ca}$ & 0 & 0.048 \\
\hline $\mathrm{Ga}$ & 0 & 0.09 \\
\hline $\mathrm{Ni}$ & 0 & 0.04 \\
\hline $\mathrm{Cr}$ & 0 & 0.038 \\
\hline $\mathrm{Cu}$ & 0 & 0.02 \\
\hline $\mathrm{S}$ & 0 & 0.005 \\
\hline $\mathrm{C}$ & 0 & 0.005 \\
\hline $\mathrm{Pb}$ & 0 & 0.006 \\
\hline $\mathrm{Se}$ & 0 & 0.005 \\
\hline $\mathrm{Cs}$ & 0 & 0.005 \\
\hline
\end{tabular}

Keeping in mind the restrictions identified above, the problem of finding feasible combinations of the impurities was considered as a mixture problem [5]. Statistical software such as JMP Version 6.0.2 is available to assist in working with such problems [6]. Using tools associated with JMP, a matrix of 60 impurity combinations was developed to facilitate the impurity testing to assess individual and interactive effects. The 60 impurity concentrations were combined with $\mathrm{HfO}_{2}$ as a surrogate for $\mathrm{PuO}_{2}$ to form the feed material. The feed was then combined with LaBS Frit X (Table II) at a mass ratio of $14 \%$ feed to $86 \%$ frit. A $14 \%$ feed value represented a nominal upper bound for "waste loading" projected for $\mathrm{Pu}$ vitrification operations.

Table II. Chemical composition of LaBS Frit X

\begin{tabular}{|c|c|}
\hline Component & wt\% \\
\hline $\mathrm{Al}_{2} \mathrm{O}_{3}$ & 10.00 \\
\hline $\mathrm{B}_{2} \mathrm{O}_{3}$ & 13.00 \\
\hline $\mathrm{Gd}_{2} \mathrm{O}_{3}$ & 13.50 \\
\hline $\mathrm{HfO}_{2}$ & 7.00 \\
\hline $\mathrm{La}_{2} \mathrm{O}_{3}$ & 19.00 \\
\hline $\mathrm{Nd}_{2} \mathrm{O}_{3}$ & 15.00 \\
\hline $\mathrm{SiO}_{2}$ & 20.00 \\
\hline $\mathrm{SrO}$ & 2.50 \\
\hline
\end{tabular}




\section{$\underline{\text { Glass fabrication and characterization }}$}

Each glass was batched from the appropriate amounts of reagent metal oxides, carbonates, sulfates, fluorides and chlorides. The batches were thoroughly mixed and melted in $\mathrm{Pt} / \mathrm{Rh}$ crucibles at $1450{ }^{\circ} \mathrm{C}$ for 1 hour. The glass was then quenched by pouring onto a stainless steel plate. The resulting glass patty and the remaining contents of the crucible were ground to a fine powder using a ring pulverizer to further aid in mixing. The glass powder was subsequently remelted at $1450{ }^{\circ} \mathrm{C}$ for one hour and quenched. Samples of each of the glasses were heat treated to simulate cooling inside a high level waste glass canister. This heat treatment allows for the identification of any crystalline phases that may form during slow cooling within the canister.

The chemical composition of each of the study glasses was measured by Inductively Coupled Plasma - Atomic Emission Spectroscopy (ICP-AES). Samples were prepared via two methods: a peroxide fusion dissolution was used for measurement of $\mathrm{B}$ concentrations and a lithium metaborate dissolution was used for measurement of the other cation concentrations. Ion Chromatography (IC) was employed to measure the concentration of the anions in each glass. Samples of the quenched and slowly cooled versions of each glass were analyzed for the presence of any crystalline phases by X-ray diffraction (XRD).

The PCT-A [7] was used to measure the durability of samples of each glass, both quenched and slowly cooled. Samples of each glass were ground to a size fraction of - 100 to +200 mesh and placed in stainless steel vessels with de-ionized water following the test procedure. The vessels were sealed and placed in an oven at $90{ }^{\circ} \mathrm{C}$ for 7 days. The leachates were then removed from each vessel, filtered, and analyzed via ICP-AES. Normalized elemental release values were calculated using the ICP-AES leach solution data and measured glass composition data.

\section{RESULTS AND DISCUSSION}

The results of the chemical composition measurements for each of the study glasses are summarized in Figure 1. A plot is shown for each of the elements (converted to an oxide) that was varied in the glass compositions (i.e., the anticipated impurity elements and the Pu surrogate Hf). 


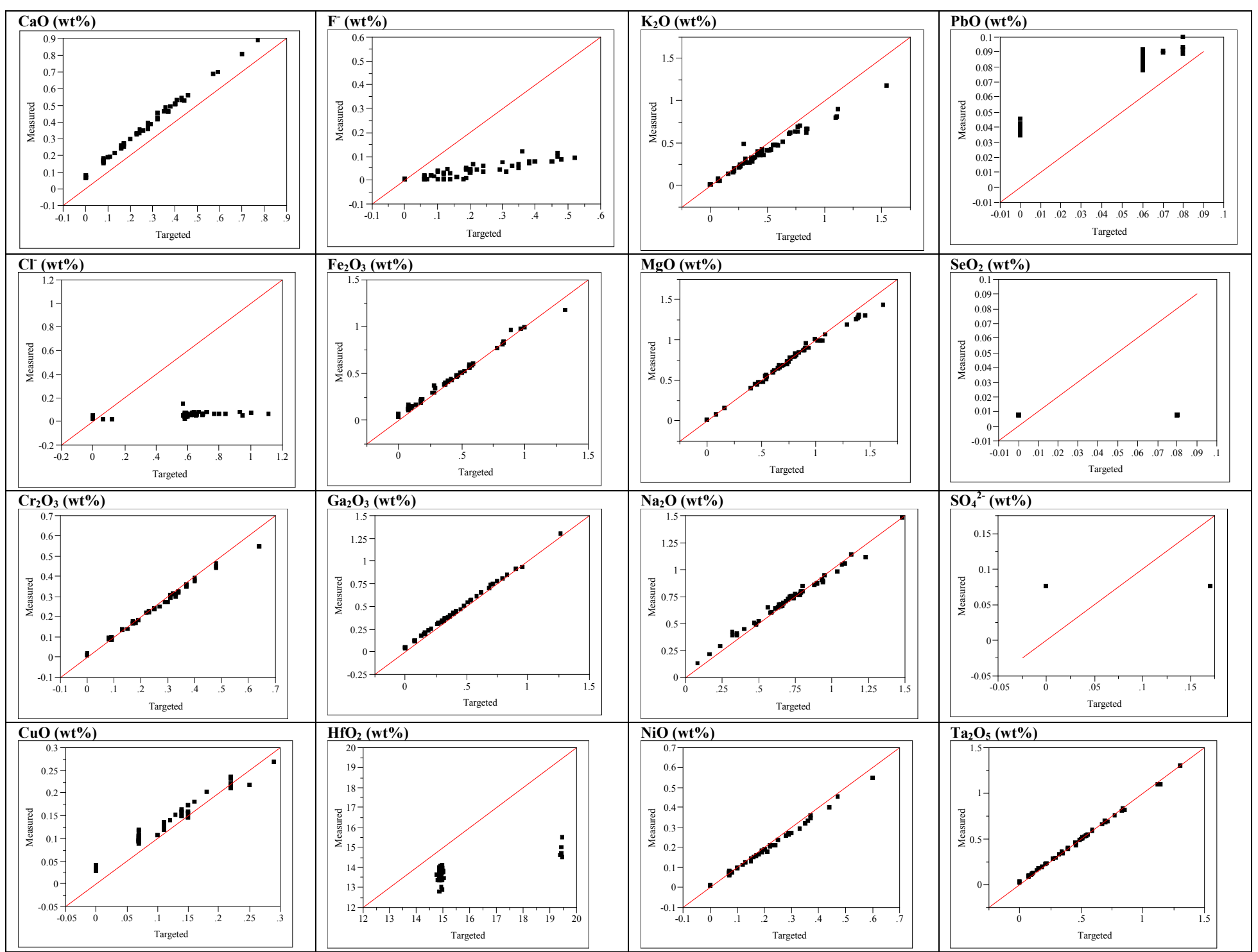

Figure 1. Measured versus Targeted Concentrations for Select Analytes in the Study Glasses 
The measured $\mathrm{CaO}$ and $\mathrm{PbO}$ concentrations were consistently higher than the targeted values. The measured $\mathrm{Cr}_{2} \mathrm{O}_{3}$ and $\mathrm{Fe}_{2} \mathrm{O}_{3}$ concentrations are very close to the targets except for the one highest targeted value for each of these components. The measured $\mathrm{Cl}^{-}, \mathrm{F}^{-}, \mathrm{SeO}_{2}$ and $\mathrm{SO}_{4}{ }^{2-}$ concentrations are well below their target values for all of the study glasses. This is likely due to volatilization of these species during melting of the glass batch. It should be noted that $\mathrm{SeO}_{2}$ and $\mathrm{SO}_{4}{ }^{2-}$ were tested at two concentration levels and volatility reduced the concentrations in the glass to below the analytical detection limit for all glasses (hence, the appearance of two data points in the plots in Figure 1). The measured $\mathrm{HfO}_{2}$ concentrations were below their target values for all of the study glasses. It is likely that for $\mathrm{HfO}_{2}$, the solubility limit in the glass was exceeded and some of the $\mathrm{HfO}_{2}$ batch material remained in the bottom of the crucibles after pouring the glasses. The measured $\mathrm{K}_{2} \mathrm{O}$ concentrations are very close to the target values up to a concentration of about $0.48 \mathrm{wt} \%$, after which the measured concentrations fall below the target values. The measured $\mathrm{MgO}$ concentrations are very close to the target values up to a concentration of about $1.1 \mathrm{wt} \%$, after which the measured concentrations fall below the target values. The measured $\mathrm{CuO}, \mathrm{Ga}_{2} \mathrm{O}_{3}, \mathrm{Na}_{2} \mathrm{O}, \mathrm{NiO}$, and $\mathrm{Ta}_{2} \mathrm{O}_{5}$ concentrations generally fall very close to their target values across the ranges of concentrations targeted in this study for each of these components.

The XRD results showed that all but two of the quenched glasses were X-ray amorphous. Two of the quenched glasses formulated with $4 \%$ impurities in the simulated Pu feed contained some crystalline $\mathrm{HfO}_{2}$. This is not surprising, as the target $\mathrm{HfO}_{2}$ concentration in these glasses was $\sim 19.5 \mathrm{wt} \%$. For the slowly cooled glasses, 3 of the 5 glasses with $4 \%$ impurities in the simulated $\mathrm{Pu}$ feed contained some crystalline $\mathrm{HfO}_{2}$. This was confirmed by Scanning Electron Microscopy (SEM) as shown in Figure 2. The $\mathrm{HfO}_{2}$ crystallites appear brighter in this backscattered electron image due to their higher average atom mass, and Energy Dispersive Spectroscopy (EDS) confirmed that the concentration of $\mathrm{Hf}$ in this crystallites was much higher than the surrounding glass matrix. The basis for the use of $\mathrm{HfO}_{2}$ as a surrogate for $\mathrm{PuO}_{2}$ in borosilicate glasses from a solubility perspective has been documented [8]. Therefore, insolubility of $\mathrm{HfO}_{2}$ at these concentrations is not unexpected since the solubility limit of $\mathrm{PuO}_{2}$ in LaBS glass was found to be $13.4 \mathrm{wt} \%$ [1]. 


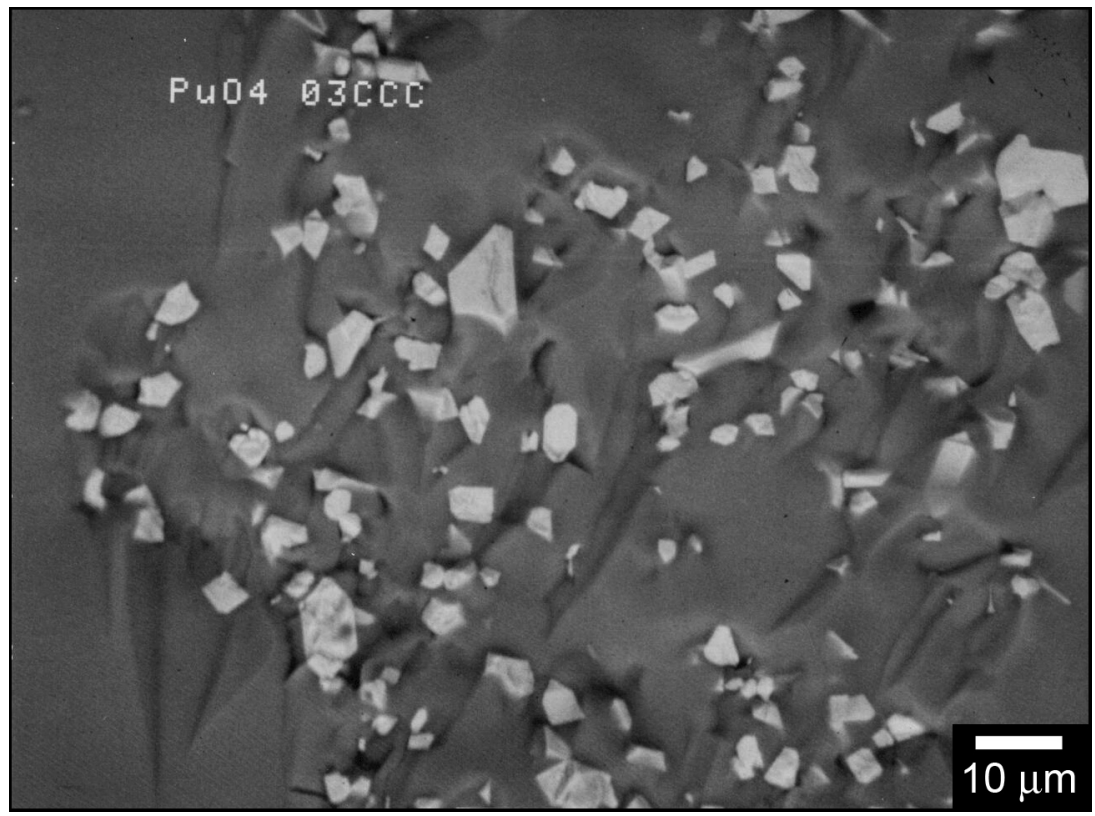

Figure 2. SEM micrograph of a LaBS glass fracture surface in an area containing undissolved $\mathrm{HfO}_{2}$ (bright crystallites).

The results of the PCTs indicated that each of the study glasses was highly durable as compared to the Environmental Assessment (EA) glass, which is used as a benchmark for defense-related waste glasses destined for the U.S. federal repository [9]. Boron has been found to be released at the same maximum normalized concentration as some high-activity radionuclides, and is therefore typically used to gauge the performance of simulated waste glasses. The concentration of B in the PCT leachates was below the detection limit of the ICPAES instrument for most of the study glasses. This is consistent with previous testing on a $\mathrm{Pu}-$ loaded LaBS glass without impurities where boron leachate values as measured by ICP-AES were also below detection limits [10]. The highest normalized release for boron measured in the study was $0.041 \mathrm{~g} / \mathrm{L}$, which is considerably smaller than that of the EA glass $(16.695 \mathrm{~g} / \mathrm{L})$. The maximum normalized release rates among the 60 glasses for the other elements measured were also quite low: $0.005 \mathrm{~g} / \mathrm{L}$ for Hf, $0.014 \mathrm{~g} / \mathrm{L}$ for $\mathrm{Gd}, 1.229 \mathrm{~g} / \mathrm{L}$ for $\mathrm{Na}$ and $0.090 \mathrm{~g} / \mathrm{L}$ for $\mathrm{Si}$. The normalized release rates for these elements were generally too small to attempt to correlate the results with the compositions of the test glasses. Note that the $\mathrm{pH}$ of the leachate solutions (typically $~ 8.0$ ) were generally lower than that of typical high-level waste glasses developed for defense-related radioactive waste sludges (typically $\sim 10.5$ ), which may have had some influence on the PCT results.

\section{CONCLUSIONS}

Sixty surrogate glass compositions were developed through a statistical design approach to cover the anticipated ranges of concentrations for the dominant impurity species expected in the $\mathrm{Pu}$ feed. These glasses were fabricated and characterized in the laboratory to determine the degree of crystallization that occurred, both upon quenching and slow cooling, and to measure the durability of each glass. XRD and SEM results indicated that some crystalline $\mathrm{HfO}_{2}$ remained in 
some of the glasses with the lowest concentration of impurities. No other significant crystalline phases were identified. The PCT results showed that all 60 of the glass compositions tested were very durable (regardless of thermal heat treatment), with the highest normalized release for boron being $0.041 \mathrm{~g} / \mathrm{L}$. The normalized release rates for these elements were generally too small to attempt to correlate the results with the compositions of the test glasses. Overall, the LaBS glass system appears to be very tolerant of the impurities projected to be included in the Pu waste stream. There was evidence of volatility especially with the anion species. Corresponding melter process testing is underway to address handling of the volatile species.

\section{REFFERENCES}

1. J.D. Vienna, D.L. Alexander, H. Li, M.J. Schweiger, D.K. Peeler and T.F. Meaker, "Plutonium Dioxide Dissolution in Glass," U.S. Department of Energy Report PNNL-11346, Pacific Northwest National Laboratory, Richland, WA (1996).

2. T.F. Meaker and D.K. Peeler, "Solubility of Independent Plutonium Bearing Feed Streams in a Hf-Based LaBS Frit, contained in: Plutonium Immobilization: The Glass Option - A Compendium of Reports and Presentations," U.S. Department of Energy Report WSRC-RP97-00902, Westinghouse Savannah River Company, Aiken, SC (1997).

3. J. R. Zamecnik, T. M. Jones, D. H. Miller, D. T. Herman and J. C. Marra, "Process Testing to Support the Design of a Plutonium Vitrification Facility," Waste Management '07 Proceedings, American Nuclear Society, Inc., LaGrange Park, IL, 2007.

4. E.N. Moore and J.S. Allender, "Projected Characteristics of Nominal Feeds to Plutonium Disposition Project," U.S. Department of Energy Report SRNL-OPD-2007-00008, Washington Savannah River Company, Aiken, SC (2007).

5. J.A. Cornel, Experiments with Mixtures: Designs, Models, and the Analysis of Mixture Data, John Wiley and Sons, New York (2002).

6. $J M P^{T M}$, Ver. 6.0.2, [Computer Software] SAS Institute Inc., Cary, NC (2005).

7. ASTM, "Standard Test Methods for Determining Chemical Durability of Nuclear Waste Glasses: The Product Consistency Test (PCT)," ASTM C-1285, (2002).

8. C. Lopez, X. Deschanels, J.M. Bart, J.M. Boubals, C. Den Auwer and E. Simoni, "Solubility of Actinide Surrogates in Nuclear Glasses," Journal of Nuclear Materials, 312 (2003) 76-80.

9. C.M. Jantzen, N. E. Bibler, D. C. Beam, C. L. Crawford and M. A. Pickett, "Characterization of the Defense Waste Processing Facility (DWPF) Environmental Assessment (EA) Glass Standard Reference Material," U.S. Department of Energy Report WSRC-TR-92-346, Revision 1, Westinghouse Savannah River Company, Aiken, SC (1993).

10. J.C. Marra, C.L. Crawford and N.E. Bibler, "Glass Fabrication and Product Consistency Testing of Lanthanide Borosilicate Frit X Composition for Plutonium Disposition," U.S. Department of Energy Report WSRC-STI-2006-00318, Washington Savannah River Company, Aiken, SC (2006). 